Eixo Temático: Biologia Aplicada

\title{
ET-09-003 \\ MUSGOS ACROCÁRPICOS DE UM REMANESCENTE DE FLORESTA ATLÂNTICA, FAZENDA PATIOBA, ALAGOINHAS, BAHIA, BRASIL
}

\author{
Milena Evangelista ${ }^{1}$, Gracineide Selma Santos de Almeida²
}

${ }^{1}$ Graduanda da Universidade do Estado da Bahia - UNEB Campus II.

${ }^{2}$ Professora da Universidade do Estado da Bahia - UNEB Campus II.

http://dx.doi.org/10.21472/congrebio2016.et-09-003

\section{RESUMO}

Considerando a escassez de estudos florísticos envolvendo os musgos acrocárpicos para o Estado da Bahia, assim como para o município de Alagoinhas, o estudo da flora de musgos acrocárpicos no remanescente de Floresta Atlântica, na Fazenda Patioba, no Município de Alagoinhas, caracteriza-se como pioneiro o que possibilita a descrição de espécies endêmicas desta área. As coletas foram realizadas a cada bimestre em áreas de borda e interior da Floresta, os espécimes acondicionados em sacos de $1 \mathrm{~kg}$ para transporte e armazenamento, depositados e herborizados no Herbário da Universidade do Estado da Bahia (HUNEB) para o tratamento taxonômico, quando necessário, especialistas foram consultados para a confirmação das espécies. Foram identificadas e confirmadas 10 espécies, distribuídas em 7 gêneros e 4 famílias. Dados como caracterização taxonômica, distribuição geográfica para o Brasil e biocenose das espécies estudadas foram abordadas. "Fundação de Amparo à Pesquisa do Estado da Bahia FAPESB”.

Palavras-chave: Floresta Atlântica; Alagoinhas; Taxonomia; Acrocárpicos.

\section{INTRODUÇÃO}

Distribuídas nas divisões Marchantiophyta (hepáticas), Anthocerotophyta (antóceros) e Bryophyta (musgos) (SHAW e GOFFINET, 2000), as Briófitas compõem um grande grupo de espécies vegetais, que possuem características muito peculiares. Nos musgos há uma divisão entre espécies quanto a posição do periquécio, nos musgos acrocárpicos este se encontra no ápice do ramo principal do gametófito, enquanto que nos musgos pleurocárpicos o periquécio se encontra lateralmente ao ramo secundário. Os musgos acrocárpicos são comumente encontrados formando densos tapetes o que acarreta em interações ecológicas muito importantes com pequenos invertebrados.

Para o Estado da Bahia os estudos se concentram em sua grande maioria no ambiente de Floresta Atlântica, o que não inviabiliza levantamentos em áreas com outros domínios fitogeográficos. Para o Estado estima-se 252 espécies de musgos (COSTA et al., 2011), e sendo que $50 \%$ deste total corresponda a musgos Acrocárpicos.

De acordo com Vilas Bôas-Bastos (2008), trabalhos sobre a Brioflora da Mata Atlântica, são fundamentais para o conhecimento da composição florística, estrutura das comunidades, diversidade específica, assim como a distribuição e da relação entre espécies e seu microambiente. Essas características salientam a importância na continuidade de pesquisas, afim de aprimorar a literatura sobre a composição florística dos Fragmentos da Floresta Atlântica encontrados no Brasil.

Para o Estado da Bahia há algumas referências de levantamentos da Brioflora, como os trabalhos de Vilas Bôas-Bastos (2008), Bastos et al. (2010) e Ballejos e Bastos (2010). Este último se dedicou no levantamento da Brioflora de musgos Acrocárpicos, registrando 29 
espécies, deste total três representam novas ocorrências para a Bahia e quatro para a Região Nordeste.

O presente trabalho tem como finalidade o levantamento da flora de musgos Acrocárpicos de um Fragmento de Floresta Atlântica na fazenda Patioba, que fornecerá dados para o conhecimento da flora de musgos da Bahia além de enfatizar as espécies endêmicas de Floresta Atlântica e possíveis novas ocorrências para o Estado da Bahia, possibilitando ações futuras de conservação da área de estudo.

\section{METODOLOGIA}

A Fazenda Patioba está localizada a $23 \mathrm{~km}$ da sede do Município de Alagoinhas, em direção à BR 101, sentido Inhambupe. A área de estudo corresponde a um remanescente Ombrófilo Denso de Floresta Atlântica. Sua fisionomia é caracterizada pela presença de árvores de médio e grande porte formando uma copa densa. A área possui aproximadamente 40 hectares, segundo dados calculados com auxílio do programa Google Earth Pro (Figura 1).

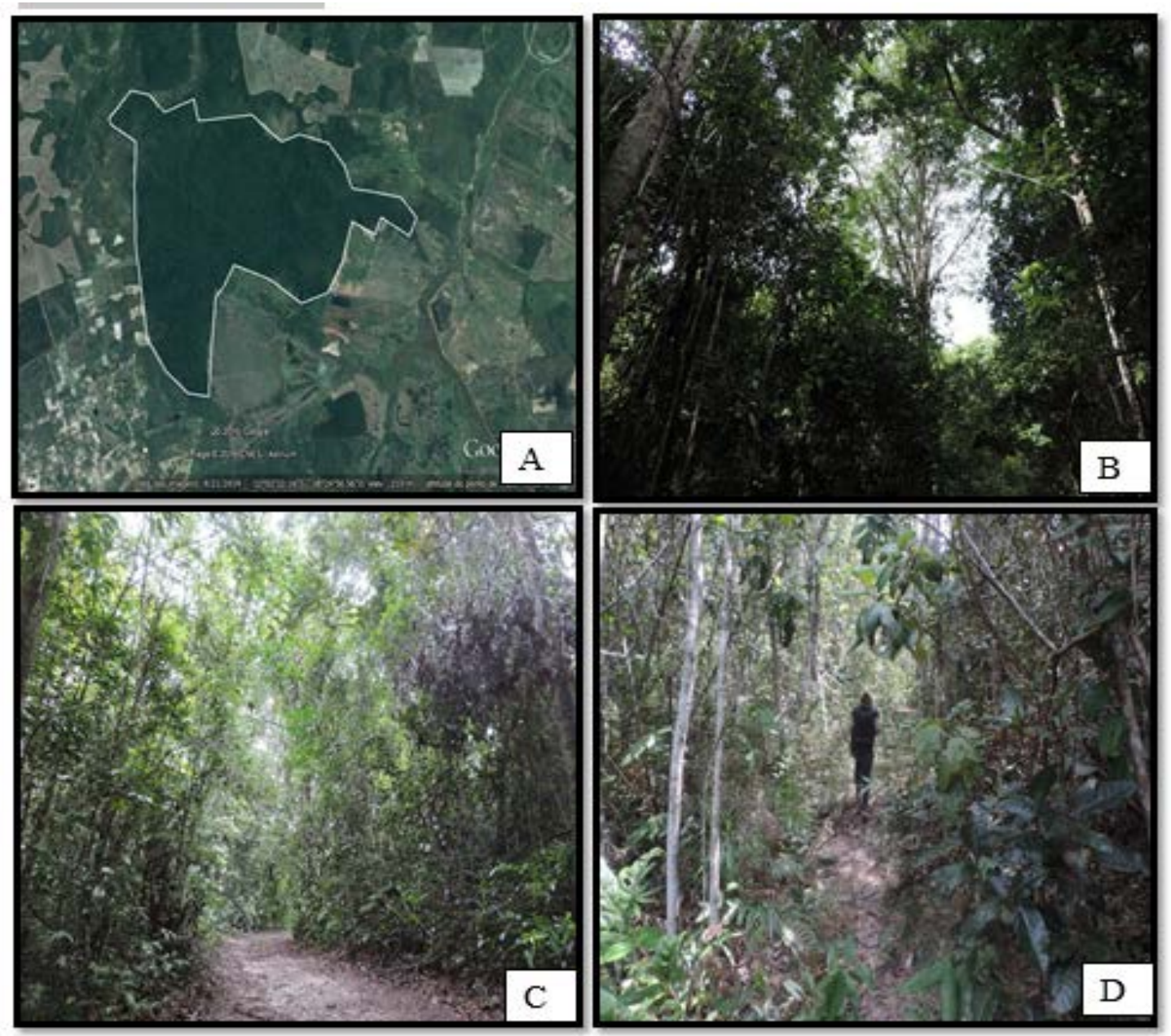

Figura 01. A. Imagem retirada do programa Google Eart, com a delimitação da área com auxílio doas ferramentas de editoração fornecidas pelo mesmo programa, B. Dossel, C e D trilhas.

As coletas foram realizadas a cada bimestre durante o período de um ano (2015/2016), em trilhas preestabelecidas, quando possível o material foi coletado em trilhas fechadas, com o 
subsídio de um guia. As espécies foram coletadas com o substrato, já que este possui grande importância taxonômica. Para a distribuição geográfica foi utilizada a literatura de Costa et al. (2011), sendo esta uma das mais recentes para o Brasil. O material identificado está sendo catalogado e registrado no banco de dados do Herbário da Universidade do Estado da Bahia (HUNEB).

\section{RESULTADOS E DISCUSSÃO}

Foram identificadas 10 espécies, distribuídas em 7 gêneros e 4 famílias. Verificou-se uma variação dos táxons de acordo com a precipitação, e distanciamento da região antropizada.

Tabela 1. Checklist das famílias, gêneros, espécies e biocenose amostradas no fragmento de Floresta Atlântica, Fazenda Patioba, Bahia, Brasil.

\begin{tabular}{|c|c|c|c|}
\hline Família & Gênero & Espécie & Biocenose \\
\hline \multirow[t]{2}{*}{ Bryaceae Schwägr } & \multirow[t]{2}{*}{ Bryum Hedw. } & B. billardieri Schwägr & Terrícola \\
\hline & & B. densifolium Brid. & $\begin{array}{l}\text { Terrícola } \\
\text { Epixílica }\end{array}$ \\
\hline \multirow[t]{4}{*}{ Calymperaceae Kindb. } & $\begin{array}{l}\text { Calymperes Sw. ex F. } \\
\text { Weber }\end{array}$ & C. palisotii Schwägr. & Corticícola \\
\hline & $\begin{array}{l}\text { Octoblepharum } \\
\text { Hedw. }\end{array}$ & O. albidun Hedw. & Corticícola \\
\hline & \multirow{2}{*}{$\begin{array}{l}\text { Syrrophodon } \\
\text { Schwägr. }\end{array}$} & S. paratitticus (Brid.) Besch & Corticícola \\
\hline & & S. prolifer Schwägr. var. prolifer & Epixílica \\
\hline \multirow[t]{3}{*}{ Fissidentaceae Schimp. } & \multirow[t]{3}{*}{ Fissidens Hedw. } & F. lindbergii Mitt. & Terrícola \\
\hline & & F. palmatus Hedw. & Terrícola \\
\hline & & F. zollingeri Mont. & Terrícola \\
\hline Leucobryaceae Schimp. & Campylopus Brid. & C. savannarum (Müll.Hal.) Mitt & Terrícola \\
\hline
\end{tabular}

\section{BRYACEAE}

As espécies desta família são comumente encontradas formando densos tufos, em sua grande maioria desenvolvem-se como epixílicas, corticícolas ou terrícolas. Seus gametófitos apresentam uma coloração verde, algumas vezes verde-amarelado. De acordo com Sharp et al. (2014), as espécies possuem filídios numerosos, alguns arranjados em rosetas, apresentam costa bem desenvolvida e raramente são ecostados. Os filídios apresentam formatos variados, podendo ser lanceolados, ovalados ou oblongos.

Chave analítica para as espécies de Bryaceae encontradas na Floresta Atlântica, Fazenda Patioba:

1. Gametófitos pequenos com até $6 \mathrm{~mm}$ de comprimento, filídios enrolados quando secos, ápice agudo e denticulado 1. Bryum billadieri

1'. Gametófitos grandes, atingindo até $45 \mathrm{~mm}$, filídios eretos quando secos raramente convolutos, ápice acuminado e serrulado..... 2.

2. Bryum densifolium 
Bryum billardieri Schwägr

Gametófitos com 5-6 mm de comprimento; filídios oblongo-lanceolado eretos e levemente enrolados quando secos, 2-3 mm de comprimento, ápice agudo e denticulado, base oblonga, costa curto- excurrente, margem inteira, bordo formado por 2 fileiras de células hialinas e alongadas, células superiores hexagonais lisas e células alares retangulares hialinas.

Material examinado: BRASIL. Bahia: Alagoinhas, Fazenda Patioba, 02-Jun-2015, M. EVANGELISTA 30 (HUNEB).

Distribuição geográfica: AM, BA, DF, ES, GO, MA, MG, MS, MT, PA, PE, PR, RJ, RO, RR, RS, SC e SP.

Comentários taxonômicos: Bryum billardieri é uma espécie encontrada formando densos tufos e possui como uma das características diagnósticas a presença de filamentos na axila do filídio.

\section{Bryum densifolium Brid.}

Gametófitos com 35-45 mm de comprimento; filídios oblongo-lanceolado eretos quando secos, 4-5 mm de comprimento, ápice acuminado e serrulada, base oblonga, costa percurrente, margem inteira, plana ou reflexa, bordo formado por 1-2(-3) fileira de células hialinas alongadas, células superiores rombo-hexagonais lisas e células alares curto retangulares.

Material examinado: BRASIL. Bahia: Alagoinhas, Fazenda Patioba, 02-jun-2015, M. EVANGELISTA 29 (HUNEB), 21-Ago-2016 M. EVANGELISTA (HUNEB).

Distribuição geográfica: BA, DF, ES, MG, PE, PR, RJ, RS, SC, SP.

Comentários taxonômicos: foi observada uma variação na coloração dos filídios de acordo com o distanciamento da entrada da Floresta e com o período de precipitação. Os indivíduos foram coletados em áreas de borda, não sendo encontrados no interior da Floresta. Poucos indivíduos apresentavam bordo formado por mais de uma fileira de células. Bryum densfolium é facilmente reconhecido pela coloração avermelhada do caulído, seu tamanho e o ápice do filídio.

\section{CALYMPERACEAE}

Caracterizada por apresentar indivíduos com gametófitos eretos, algumas vezes ramificados podendo apresentar tomentos. Filídios quando secos eretos, enrolados ou arranhados de forma helicoidal. Costa simples. Base do filídio geralmente sendo formada por células hialinas, variando em sua morfologia. As células medianas normalmente podem ser lisas ou mamilosas.

Chave analítica para as espécies de Calymperaceae encontradas na Floresta Atlântica, Fazenda Patioba.

1. Gametófitos até $5 \mathrm{~mm}$, filídio linear lanceolado

2. Filídios unipapilosos, bordo ausente, lanceolados, ápice agudo

2'. Filídios pluripapilosos, bordeado, linear, ápice obtuso geralmente com gemas.................................................... 4. Syrropodon prolifer var. prolifer

4. Syrropodon prolifer var. prolifer
(8) mm, filídio oblongo ou ligulado

3. Filídios ligulados, esbranquiçados, costa

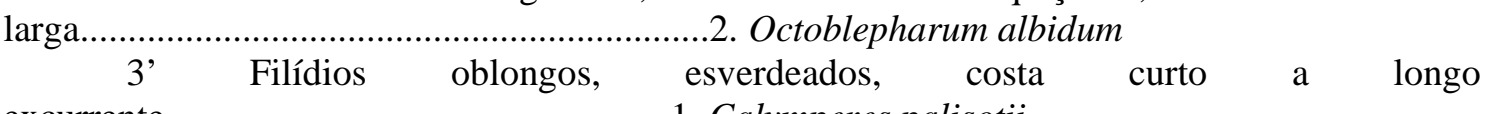

excurrente. 1. Calymperes palisotii

Calymperes palisotii Schwägr.

Gametófitos com 6-7 mm de comprimento; filídios oblongo enrolados quando secos, 2-3 mm de comprimento, ápice tubular com propágulos 2-3 células de comprimento irregularmente denteada, base oblonga, costa curto excurrente a longo excurrente com papilas, margem inteira, bordo formado por 2-3 fileiras de células hialinas quadráticas ou romboidais, 
células superiores romboidais maminolas, células alares quadráticas, as marginais são mais alongadas em 2-3 fileiras.

Material examinado: BRASIL. Bahia: Alagoinhas, Fazenda Patioba, 27-jan-2016, M. EVANGELISTA 100 (HUNEB)).

Distribuição geográfica: AL, AM, AP, BA, CE, ES, GO, MA, PA, PB, PE, PI, MT, PR, RJ, RN, RO, RR, SE, SP, TO.

Comentários taxonômicos: espécie é caracterizada pela costa excurrente, com propágulos hialinos dispostos em tufos. A coloração verde-escura e formato oblongo dos filídios também contribuíram para a confirmação da espécie.

Octoblepharum albidun Hedw.

Gametófito com 6-8 mm de comprimento; filídios ligulado, estendidos quando secos, 4$6 \mathrm{~mm}$ de comprimento, ápice mucrunado serreado, base oblonga, costa larga ocupando maior parte da lâmina, margem inteira, sem bordo, células superiores romboidais, basais hialinas e retangulares.

Material examinado: BRASIL. Bahia: Alagoinhas, Fazenda Patioba, 28-Abr-2016, M, EVANGELISTA 21 (HUNEB).

Distribuição geográfica: de acordo com Bastos et al. (2010) a espécie tem ampla distribuição na Bahia. Para o Brasil ela é reportada para todos os Estados.

Comentários taxonômicos: é uma espécie que pode ser facilmente reconhecida pela disposição dos filídios, coloração esbranquiçada, costa larga e ápice mucrunado.

Syrrhopodon parasitticus (Brid.) Besch.

Gametófito com 4-5 mm de comprimento; filídios unipapiloso, lanceolado, contorcidos quando secos, 4-5 mm de comprimento, ápice agudo, base oblonga, costa percurrente, margem lisa, sem bordo, células superiores quadráticas, células alares hialinas e retangulates.

Material examinado: BRASIL. Bahia: Alagoinhas, Fazenda Patioba, 02-Jun-2016, M. EVANGELISTA 26 (HUNEB).

Distribuição geográfica: AC, AM, BA, DF, ES, GO, MG, MS, MT, PA, PE, PR, RJ, RO, RR, SC, SP.

Comentários taxonômicos: a espécie destaca-se pela presença de propágulos filamentosos e células unipapilosas. Em alguns indivíduos observou-se uma variação no bordo, apresentando-se completo ou não até o ápice, característica esta comum quando observado em outros trabalhos como nos trabalhos de Sousa (2013).

Syrrhopodon prolifer Schwägr. var. prolifer.

Gametófito com 3-4 mm de comprimento; filídios pluripilosos, linear, contorcidos quando secos, $2 \mathrm{~mm}$ de comprimento, ápice obtuso com gemas apicais, base obtusa, costa estreita e percurrente, margem lisa, bordo com 1-2 fileiras de células hialinas e delgadas, células superiores isodiamétricas, células alares romboidais.

Material examinado: BRASIL. Bahia: Alagoinhas, Fazenda Patioba, 02-jun-2016, M, EVANGELISTA 28 (HUNEB).

Distribuição geográfica: AL, AM, AP, BA, DF, ES, MG, GO, MT, PA, PE, PI, PR, RJ, RO, RS, SC, SE, SP, TO.

Comentários taxonômicos: esta variedade se caracteriza por possuir filídios pluripapilosos e lineares. Diferencia de S. prolifer var. scaber, pois este possui ápice denteado, células densamente pluripapilosas com papilas abauladas, como descreve Ballejos \& Batos (2010).

\section{FISSIDENTACEAE}

É caracterizada pela presença de limbídia que corresponde a um conjunto de células diferenciadas localizadas na região marginal do filídio, assim como a presença de uma lâmina vaginante que corresponde a uma modificação no filídio. Além destas duas características 
marcantes, algumas espécies ainda apresentam nódulos hialinos, que são estruturas encontradas no caulídio.

Chave analítica para as espécies de Fissidentaceae encontradas na Floresta Atlântica, Fazenda Patioba:

1. Costa subpercurrente, células superiores romboidais, retangulares ou curto-hexagonais

2. Filídios com ápice agudo, limbídia com até 2 fileiras de células alongadas, células superiores romboidais 1. Fissidens lindbergii

2’ $\quad$ Filídios com ápice curto apiculado, limbídia com mais de 2 fileiras de células romboidais, células superiores retangulares ou curtohexagonais 2. Fissidens palmatus

1' Costa percurrente, células superiores hexagonais 3. Fissidens zolingeri

Fissidens lindbergii Mitt.

Gametófitos com 3-4 mm de comprimento; filídios flabelados, 1-2 mm de comprimento, ápice agudo, base oblonga, costa subpercurrente, margem lisa, limbídia em todo o filídio com 1-2 fileiras de células alongadas, lâmina vaginante até a metade do filídio, células superiores romboidais, células alares retangulares.

Material examinado: BRASIL. Bahia: Alagoinhas, Fazenda Patioba, 21-Ago-2016, M. EVANGELISTA 45 (HUNEB). RJ.

Distribuição geográfica: Para o Brasil a espécie foi reportada para os Estados BA, GO,

Comentários taxonômicos: a espécie foi encontrada na borda da Floresta. Esta espécie pode apresentar uma célula apical avermelhada ou amarelada como descreve Bordin \& Yano (2013), porém nos indivíduos analisados não se observou essa característica. Para o Estado da Bahia foi citada por Oliveira \& Bastos (2010) para região de chapada com a Caatinga como fitosionomia predominante, sendo, portanto, a primeira vez que é citada para região de Floresta Atlântica.

Fissidens palmatus Hedw.

Gametófito com 2-3(-4) mm de comprimento; filídios flabelados, 1-2 $\mathrm{mm}$ de comprimento, ápice curto apiculado, base oblonga, costa subpercurrente, margem lisa, limbídia em todo o filídio com 2-3 fileiras de células romboidais, lâmina vaginante até metade do filídio, células superiores retangulares ou curto hexagonais, células alares hexagonais e hialinas.

Material examinado: BRASIL. Bahia: Alagoinhas, Fazenda Patioba, 28-Abr-2016, M. EVANGELISTA 06 (HUNEB).

Distribuição geográfica: AC, AM, BA, CE, DF, GO, MG, MT, PA, PE, RJ, RO, SP.

Comentários taxonômicos: Fissidens palmatus possui o tamanho da costa muito variável, seu gametófito possui um tom verde-amarelado e sem nódulos axilares. É uma espécie comumente encontrada em áreas de Floresta Atlântica, foi coletada em região de borda.

\section{Fissidens zollingeri Mont}

Gametófito com 3-4 mm de comprimento; filídios flabelados, 2-3 mm de comprimento, ápice agudo, base oblonga, costa forte percurrente, margem lisa, limbídia em toda a lâmina 1-2 fileiras de células hexagonais hialinas, lâmina vaginante até metade do filídio, células superiores hexagonais de paredes espessas, células alares retangulares e hialinas.

Material examinado: BRASIL. Bahia: Alagoinhas, Fazenda Patioba, 28-abr-2016, M. EVANGELISTA 15 (HUNEB).

Distribuição geográfica: a espécie é reportada no Brasil para os Estados AC, AL, AM, AP, BA, CE, DF, ES, GO, MA, MG, MS, MT, PA, PB, PE, PI, PR, RJ, RO, RR, RS, SC, EP, TO.

Comentários taxonômicos: encontrada também em região de borda, a espécie se caracteriza pela limbídia em toda extensão da lâmina normalmente em 2 fileiras. 


\section{LEUCOBRYACEAE}

A família é caracterizada por gametófitos robustos formando densos tapetes ou tufos, a grande maioria das espécies possuem costa larga com mais de uma camada de células, a região alar geralmente formada por células hialinas de formatos variados. Podem apresentar bordo ou não.

1. Campylopus savannarum (Müll.Hal.) Mitt

Gametófitos grandes, alcançando $50 \mathrm{~mm}$ de comprimento, podem ser ramificados ou não; filídios fortemente agregados, eretos, 6-7 mm de comprimento, ápice hialino, acuminado, base oblonga serreado, costa larga e excurrente, margem lisa, sem bordo, células superiores romboidais, células alares retangulares.

Material examinado: BRASIL. Bahia: Alagoinhas, Fazenda Patioba, 02-jun-2016, M. EVANGELISTA 27 (HUNEB).

Distribuição geográfica: AM, BA, CE, ES, GO, MA, MG, MS, MT, PA, PE, PI, PR, RJ, RO, RR, SE, SP.

Comentários taxonômicos: a espécie foi encontrada na borda da Floresta formando densos tapetes. Em seção transversal foi observado hialocistos com predes espessas, estereídeos intercalados com os hialocistos e costelas com uma fileira de células de altura. Seu gametófito possui muitos tomentos avermelhados que geralmente ficam aderidos aos filídios quando destacados. Os filídios são maiores que os relatados por Sousa (2013), isso se deve devido as variações do ápice, retratado por Santos (2011).

\section{CONCLUSÕES}

Diante a apresentação dos resultados preliminares, pode-se concluir que a família que teve maior representatividade dentre os táxons foi Calymperaceae com 4 espécies, seguida de Fissidentaceae com 3 espécies. Todas as espécies ocorreram em áreas de borda, sendo as mesmas comuns de Floresta Atlântica. A biocenose predominante foi a terrícola, seguida de corticícola e epixílica. Todas as espécies listadas são ocorrentes para o Estado. A área de estudo se encontra em bom estado de conservação o que acarreta na necessidade da continuação dos estudos florísticos.

\section{AGRADECIMENTOS}

A autora agradece a Universidade Estadual da Bahia - UNEB, ao Departamento de Ciências Exatas e da Terra - DCET, à Fundação de Amparo e Pesquisa do Estado da Bahia FAPESB pela bolsa de Iniciação Científica, à professora Dr. Gracineide Selma Santos de Almeida, ao Herbário da Universidade do Estado da Bahia - HUNEB, a Universidade Federal da Bahia - UFBA, ao Herbário Alexandre Leal Costa - ALCB, aos professores Dr. Cid José Passos Bastos e Ms. Silvana Brito Vilas Boas-Bastos.

\section{REFERÊNCIAS}

BALLEJOS, J.; BASTOS, C.J.P. Musgos acrocárpicos do Parque Estadual das Sete Passagens, Miguel Calmon, Bahia, Brasil. Revista Brasileira de Botânica, v. 33, p. 355-370, 2010.

BASTOS, C. J. P.; YANO, O.; VILAS BÔAS-BASTOS, S. B. Briófitas de campos rupestres da Chapada Diamantina, Estado da Bahia, Brasil. Revista Brasileira de Botânica, v. 33, p. 357368, 2010.

BORDIN, J.; YANO, O. Fissidentaceae (Bryophyta) do Brasil. Boletim do Instituto de Botânica, 2013. 
COSTA, D. P.; PÔRTO, K. C.; LUIZI-PONZO, A. P.; ILKIU-BORGES, A. L.; BASTOS, C. J. P.; CÂMARA, P. E. A. S.; PERALTA, D. F.; BÔAS-BASTOS, S. B. V.; IMBASSAHY, C. A. A.; HENRIQUES, D. K.; GOMES, H. C. S.; ROCHA, L. M.; SANTOS, N. D.; SIVIERO, T. S.; VAZ-IMBASSAHY, T. F.; CHURCHILL, S. P. Synopsis of the Brazilian moss flora: checklist, distribution and conservation. Nova Hedwigia, v. 93, p. 277-334, 2011.

OLIVEIRA, H. C.; BASTOS, C. J. P. Fissidentaceae (Bryophyta) da Chapada da Ibiapaba, Ceará, Brasil. Revista brasileira de Botânica, v. 33, p. 393-405, 2010.

SANTOS, M. B. Contribuição ao conhecimento do gênero Campylopus Brid. (Bryophyta, Leucobryaceae) no Nordeste do Brasil. Feira de Santana: Universidade de Feira de Santana, 2011.

SHAW, A. J.; GOFFINET, B. Bryophyte biology. London: Cambridge University Press, 2000.

SHARP, A. J.; CRUM, H.; ECKEL, P. M. The moss flora of México. New York: The New York Botanical Garden, 1994.

SOUSA, R. V. Levantamento da brioflora de uma mata de galeria no Parque Nacional da Serra do Cipó, MG - Brasil. Brasília: Universidade de Brasília, 2013.

VILAS BÔAS-BASTOS, S. B. Musgos Pleurocárpicos dos fragmentos de Mata Atlântica da reserva ecológica da Michelin, Município de Igrapiúna, Bahia, Brasil. Feira de Santana: Universidade de Feira de Santana, 2008. 